\title{
A novel D:A-friedooleanane triterpenoid and other constituents of the stem bark of Dichapetalum barteri Engl.
}

\author{
Ivan Addae-Mensah, ${ }^{a} *$ Sam Adu-Kumi $^{\mathrm{a}}$, Reiner Waibel ${ }^{\mathrm{b}}$, and Isaac V. Oppong ${ }^{\mathrm{a}}$ \\ ${ }^{a}$ Department of Chemistry, University of Ghana, Legon, Ghana \\ ${ }^{b}$ Institute of Pharmacy and Food Chemistry, University of Erlangen, Germany \\ E-mail: a-mensah@ug.edu.gh
}

Dedicated to Professor Berhanu M. Abegaz on his $60^{\text {th }}$ Birthday

\begin{abstract}
A novel pentacyclic triterpenoid, $2 \beta$-hydroxy-3-oxo-D:A-friedoolenanan-29-oic acid has been isolated from the methanol extract of the stem bark of Dichapetalum barteri, and characterised by spectroscopic methods. Also reported for the first time from the plant are two lupane-type triterpenoids betulinic acid and betulonic acid, the friedelane triterpenoids syn:canophyllal, syn:canophyllol, friedelan-3-one and friedelan-3 $\alpha$-ol (epifriedelinol), the more common triterpenoids $\beta$-sitosterol and stigmasterol, as well as seven long chain esters of ferulic acid.
\end{abstract}

Keyword: Dichapetalum barteri, Dichapetalaceae, pentacyclic triterpenoids, $2 \beta$-hydroxy-3oxo-D:A-friedooleanan-29-oic acid, betulinic acid, betulonic acid; canophyllol, canophyllal, ferulic acid esters

\section{Introduction}

Dichapetalum barteri belongs to the small family Dichapetalaceae (syn. Chailletiaceae), which is distributed throughout the world's tropical and subtropical regions. ${ }^{1}$ Some members of the family are known to be highly toxic, particularly to livestock, due to the presence of fluorinated carboxylic acids. ${ }^{2}$ The fluorinated acids have been extensively studied. However, very little is known of the non-fluorinated constituents of this plant genus. $N$-methyl alanine and $N$-methyl serine have been reported from Dichapetalum cymosun, ${ }^{3}$ while friedelin has been found in $D$. gelonoides. ${ }^{4}$

As part of our systematic investigation of the family Dichapetalaceae occurring in Ghana, we recently reported a new class of triterpenoids never reported from any other plant family. Eight of these have so far been reported, which we named Dichapetalins A to $\mathrm{H}^{5,6}$ 
Biogenetically, their basic structures are characterised by the addition of a $\mathrm{C}_{6}$ - $\mathrm{C}_{2}$-unit to a cyclodammarane skeleton. These compounds exhibit strong and selective in-vitro cytotoxicity.

In the present paper, we report the results of studies on the relatively rare species, $D$. barteri, which is said to have strong rodenticidal activity ${ }^{7}$ and is also toxic to goats. ${ }^{8}$ Fractionation of the methanol extract of the stem bark of the plant yielded a novel pentacyclic

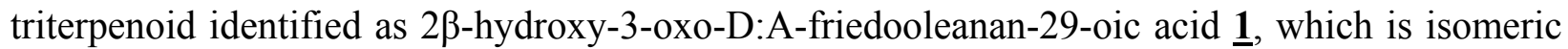
with $2 \alpha$-hydroxy populnonic acid ( $2 \alpha$-hydroxy-octandronic acid) $\underline{\mathbf{2 b}}$ and $2 \alpha$-hydroxy-3-oxoD:A-friedooleanan-30-oic acid 3a. ${ }^{9,10}$

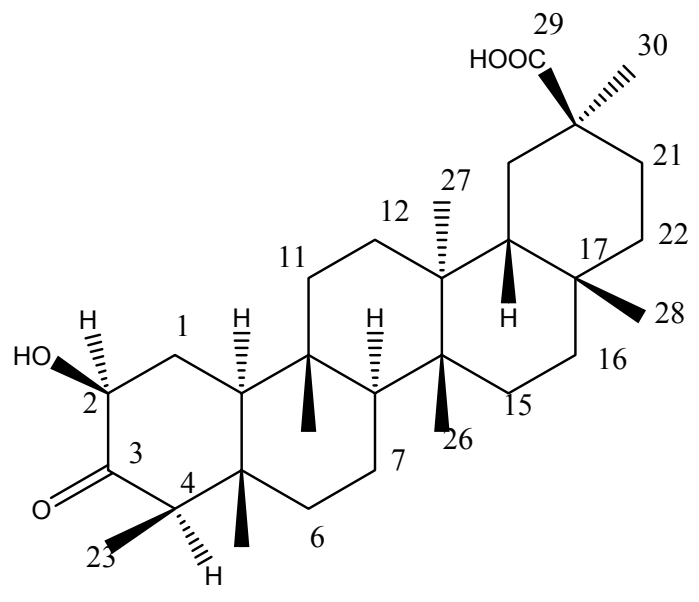

1

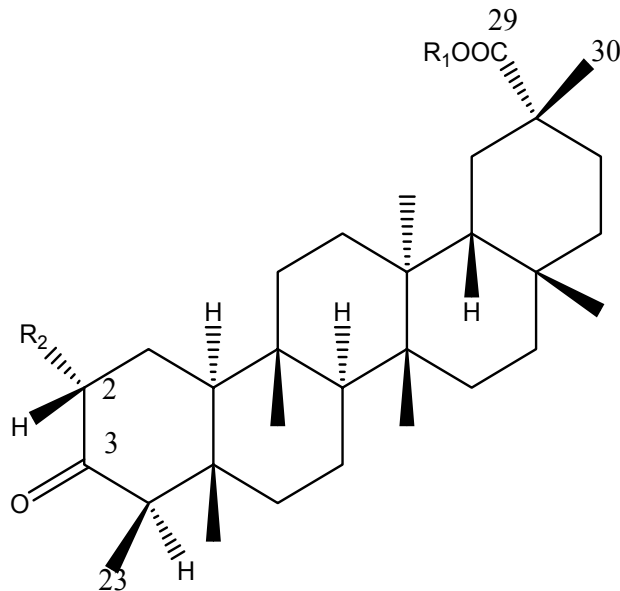

2a. $\mathbf{R}_{1}=\mathbf{R}_{\mathbf{2}}=\mathbf{H}$

$2 b \mathbf{R}_{\mathbf{1}}=\mathbf{H} ; \mathbf{R}_{\mathbf{2}}=\mathbf{O H}$

$2 c . R_{1}=M e ; R_{2}=O H$

2d. $R_{1}=M e ; R_{2}=O A c$

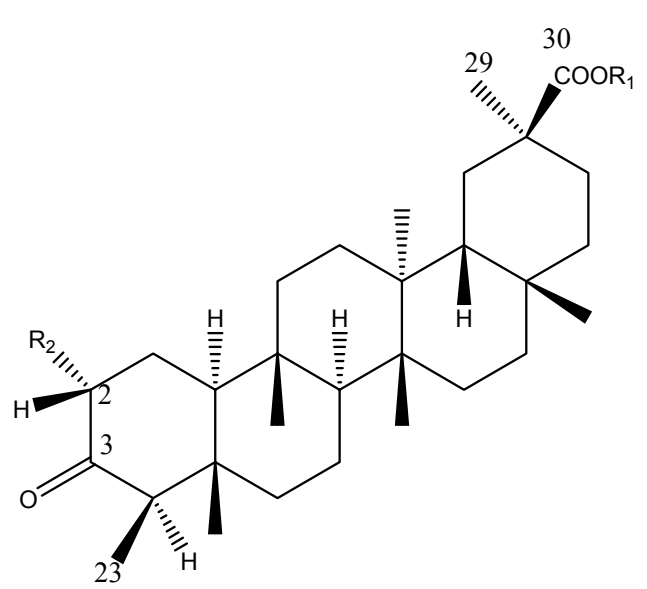

3a. $\mathbf{R}_{\mathbf{1}}=\mathbf{H} ; \mathbf{R}_{\mathbf{2}}=\mathrm{OH}$

3b. $\mathbf{R}_{1}=\mathrm{Me} ; \mathrm{R}_{2}=\mathrm{OH}$

3c. $R_{1}=M e ; R_{2}=O A c$ 
Also obtained from the petrol and acetone extracts were several known triterpenoids including the two lupane-type triterpenoids betulinc acid and betulonic acid, as well as seven long-chain esters of E-ferulic acid with the straight chain $\mathrm{C}_{23}$ to $\mathrm{C}_{29}$ alkan-1-ols.

\section{Results and Discussion}

Column chromatography of the methanol extract of the stem bark of the plant gave five main fractions. Further purification of fraction 2 gave compound $\mathbf{1}$ as off-white needle-like crystals, mp $199-201^{\circ} \mathrm{C}$, brown with anisaldehyde reagent. MS gave a molecular ion peak at 472 , $\mathrm{C}_{30} \mathrm{H}_{48} \mathrm{O}_{4} .{ }^{1} \mathrm{H}-\mathrm{NMR}$ showed signals for six angular methyl singlets at $\delta 0.71,0.86,0.99,1.05$, 1.07 and $1.31 \mathrm{ppm}$ as well as a methyl doublet $(\mathrm{J}=7.8 \mathrm{~Hz})$ at $\delta 0.96 \mathrm{ppm}$, which was assigned to methyl protons at position 23. A signal at $\delta 2.28 \mathrm{ppm}(1 \mathrm{H}, \mathrm{q}, \mathrm{J}=7.8 \mathrm{~Hz})$, was assigned to a proton at C-4 vicinal to the C-3 carbonyl carbon. The proton geminal to the $\mathrm{OH}$ group at C-2 appears as a multiplet at $\delta 4.12$, compared to the $\mathrm{C}-2$ proton in the $\alpha$-isomer $\mathbf{2} \mathbf{b}$ which occurs at 3.96 and that of compound $\mathbf{3 a}(\delta 4.00)$. The remaining 23 protons were assigned as methylene and methine protons occurring between $\delta 2.52$ and $1.15 \mathrm{ppm}$. A broad signal at $\delta 3.7$, removed by $\mathrm{H}-\mathrm{D}$ exchange, confirmed the presence of an $\mathrm{OH}$ group. The assignment of the ${ }^{1} \mathrm{H}-\mathrm{NMR}$ signals is summarised in Table 1.

Comparison of the melting point, ${ }^{1} \mathrm{H}$ and ${ }^{13} \mathrm{C}$-NMR spectra (Tables 1 and 2 ) of compound 1 with those of populnonic acid (3-oxo-D:A friedooleanan-29-oic acid) 2a, 2 $\alpha$-hydroxy populnonic acid methyl ester (syn.2 $\alpha$-hydroxy-3-oxo-D:A-friedooleanan-29-oic acid methyl ester) 2c, 3-oxo-D:A-friedooleanan-30-oic acid methyl ester $\mathbf{3 b}$ and the acetate of $2 \alpha$-hydroxy3-oxo D:A-friedooleanan-30-oic acid methyl ester 3c suggests that compound $\mathbf{1}$ is different from all these related compounds with which it has the same basic skeleton, and confirms the presence and orientation of the carboxyl and the hydroxyl groups at C-20 and C-2 respectively, and the carbonyl group at C-3.

${ }^{13} \mathrm{C}-\mathrm{NMR}$ of the compound showed a singlet at $\delta 212.4 \mathrm{ppm}$, assigned to a C-3 ketone, and a doublet at $\delta 75.2 \mathrm{ppm}$ due to carbon 2. A signal at $\delta 183.3 \mathrm{ppm}$ was attributed to a carboxyl carbon at C-29. The remaining 27 signals in the ${ }^{13} \mathrm{C}-\mathrm{NMR}$ are $\mathrm{sp}^{3}$ - hybridised signals occurring between 75 and $6.5 \mathrm{ppm}$. DEPT measurements indicated the presence of 8 quaternary, 5 tertiary $(\mathrm{CH}), 10$ secondary $\left(\mathrm{CH}_{2}\right)$ and 7 primary $\left(\mathrm{CH}_{3}\right)$ carbons. The assignment of the ${ }^{13} \mathrm{C}$-signals using DEPT measurements are as summarised in Table 1 . Comparison of the ${ }^{13} \mathrm{C}$-signals of 1 with those of $\mathbf{2 a}, \mathbf{2 b}, \mathbf{3 b}$ and $\mathbf{3 c}$ is as summarised in table 3. 
Table 1. ${ }^{1} \mathrm{H}$ and ${ }^{13} \mathrm{C}$-NMR data for compound $\mathbf{1}$

\begin{tabular}{|c|c|c|c|c|}
\hline Carbons & DEPT & $\delta_{\mathrm{H}}(\mathrm{ppm})$ & $\delta_{\mathrm{C}}(\mathrm{ppm})$ & $\begin{array}{l}\text { HMBC long-range }{ }^{1} \mathrm{H}_{-}{ }^{13} \mathrm{C} \text { couplings. } \\
\text { Carbons to which protons are coupled }\end{array}$ \\
\hline 1 & $\mathrm{CH}_{2}$ & $2.43(2 \mathrm{H}, \mathrm{m})$ & 32.6 & $2,3,5,10$ \\
\hline 2 & $\mathrm{CH}$ & $\begin{array}{l}4.12(1 \mathrm{H}, \mathrm{m}) \\
3.7(\mathrm{OH} \mathrm{br}, \mathrm{s})\end{array}$ & 75.0 & 1 \\
\hline 3 & - & - & 212.4 & - \\
\hline 4 & $\mathrm{CH}$ & $2.28(1 \mathrm{H}, \mathrm{q}, \mathrm{J}=7.8 \mathrm{~Hz})$ & 55.6 & $3,5,10,23,24$ \\
\hline 5 & - & - & 43.1 & - \\
\hline 6 & $\mathrm{CH}_{2}$ & $\begin{array}{l}1.75,1.8(2 \mathrm{H}, \text { not well } \\
\text { resolved even in } \\
\text { expanded spectrum })\end{array}$ & 41.2 & $5,7,8,10$ \\
\hline 7 & $\mathrm{CH}_{2}$ & $* *$ & 18.1 & - \\
\hline 8 & $\mathrm{CH}$ & $1.38(\mathrm{IH}, \mathrm{m})$ & 53.2 & $5,6,7,9,10,13,14,26$ \\
\hline 9 & - & - & 37.4 & - \\
\hline 10 & $\mathrm{CH}$ & $1.54(1 \mathrm{H}, \mathrm{m})$ & 56.5 & $1,2,3,5,9,11,14,24$ \\
\hline 11 & $\mathrm{CH}_{2}$ & $1.50(2 \mathrm{H}, \mathrm{m})$ & 35.3 & $1,10.12 .14 .25$ \\
\hline 12 & $\mathrm{CH}_{2}$ & $1.45(2 \mathrm{H} \mathrm{m})$ & 30.2 & $10,11,13,14,25,27$ \\
\hline 13 & - & - & $39.7 * \mathrm{~s}$ & - \\
\hline 14 & - & - & $38.1 * \mathrm{~s}$ & - \\
\hline 15 & $\mathrm{CH}_{2}$ & ** & 32.8 & \\
\hline 16 & $\mathrm{CH}_{2}$ & ** & 35.4 & - \\
\hline 17 & - & - & $29.6 \mathrm{~s}$ & - \\
\hline 18 & $\mathrm{CH}$ & $1.60(1 \mathrm{H} \mathrm{m})$ & 42.5 & $11,12,13,17,19,20,27$ \\
\hline 19 & $\mathrm{CH}_{2}$ & $\begin{array}{l}1.98(2 \mathrm{H}, \mathrm{dd} \mathrm{J}=12.5 \\
\left.\mathrm{J}_{2}=5.5 \mathrm{~Hz}\right)\end{array}$ & 31.3 & - \\
\hline 20 & - & - & $40.3 \mathrm{~s}$ & - \\
\hline 21 & $\mathrm{CH}_{2}$ & $\begin{array}{l}\mathrm{dd}, \mathrm{J}_{1}=13.5 \mathrm{~Hz} \\
\mathrm{~J}_{2}=5.0 \mathrm{~Hz}\end{array}$ & 28.2 & - \\
\hline 22 & $\mathrm{CH}_{2}$ & $* *$ & 38.2 & - \\
\hline 23 & $\mathrm{CH}_{3}$ & $0.96(3 \mathrm{H}, \mathrm{d}, \mathrm{J}=7.8 \mathrm{~Hz})$ & 6.5 & $3,4,5$ \\
\hline 24 & $\mathrm{CH}_{3}$ & $0.71(3 \mathrm{H}, \mathrm{s})$ & 14.7 & $4,5,6,10$ \\
\hline 25 & $\mathrm{CH}_{3}$ & $0.86(3 \mathrm{H}, \mathrm{s})$ & 17.8 & $8,9,10,11$ \\
\hline 26 & $\mathrm{CH}_{3}$ & $0.99(3 \mathrm{H} \mathrm{s})$ & 20.9 & $8,13,14,15$ \\
\hline 27 & $\mathrm{CH}_{3}$ & $1.05(3 \mathrm{H} \mathrm{s})$ & 17.7 & $12,13,14,18$ \\
\hline 28 & $\mathrm{CH}_{3}$ & $1.07(3 \mathrm{H} \mathrm{s})$ & 31.8 & $16,17,18,22$ \\
\hline 29 & - & - & 183.3 & - \\
\hline 30 & $\mathrm{CH}_{3}$ & $1.31(3 \mathrm{H}, \mathrm{s})$ & 32.0 & $19,20,21$ \\
\hline
\end{tabular}

*Interchangeable values **Signals not well resolved 
Table 2. Comparison of ${ }^{1} \mathrm{H}-\mathrm{NMR}$ spectral data for compounds $1,2 \mathrm{c}, 2 \mathrm{~d}, 3 \mathrm{a}$ and $3 \mathrm{c}[9,10] \delta_{\mathrm{H}}$ (ppm) (in $\left.\mathrm{CDCl}_{3}\right)$

\begin{tabular}{llllll}
\hline Position & \multicolumn{1}{c}{$\mathbf{1}$} & \multicolumn{1}{c}{ 2c } & 2d & 3a & 3c \\
\hline 2 & $* 4.12(1 \mathrm{H}, \mathrm{m}) ;$ & $3.96 \mathrm{q}$ & $4.89 \mathrm{br} . \mathrm{s}$ & $4.00 \mathrm{dd}$ & \\
& $3.7(\mathrm{OH} \mathrm{br}, \mathrm{s})$ & & & - & \\
3 & - & - & - & & \\
4 & $* 2.28(1 \mathrm{H}, \mathrm{q}, \mathrm{J}=7.8 \mathrm{~Hz})$ & $2.92 \mathrm{q} . \mathrm{J}=7$ & $2.62 \mathrm{q}$ & $2.90 \mathrm{q}$ & $2.64 \mathrm{q}$ \\
19 & $1.98\left(1 \mathrm{H}, \mathrm{dd}, \mathrm{J}_{1}=12.5 \mathrm{~Hz}\right.$, & & & \\
& $\left.\mathrm{J}_{2}=5.5 \mathrm{~Hz}\right)$ & & & & \\
22 & - & $0.97 \mathrm{dd}, \mathrm{J}_{1}=13.5,0.95 \mathrm{br}$ & & \\
& & $\mathrm{J}_{2}=4$ & & & $0.69 \mathrm{~s}$ \\
23 & $* 0.96(3 \mathrm{H}, \mathrm{d}, \mathrm{J} 7.8 \mathrm{~Hz})$ & $0.84 \mathrm{~d}$ & $0.86 \mathrm{~d}$ & $0.76 \mathrm{~d} \mathrm{~J} 6.7$ & $0.88 \mathrm{~d}$ \\
24 & $0.71(3 \mathrm{H}, \mathrm{s})$ & $0.64 \mathrm{~s}$ & $0.67 \mathrm{~s}$ & & $0.86 \mathrm{~s}$ \\
25 & $0.86(3 \mathrm{H}, \mathrm{s})$ & $0.86 \mathrm{~s}$ & $0.82 \mathrm{~s}$ & & $0.87 \mathrm{~s}$ \\
26 & $0.99(3 \mathrm{H} \mathrm{s})$ & $0.86 \mathrm{~s}$ & $0.82 \mathrm{~s}$ & & $1.08 \mathrm{~s}$ \\
27 & $* 1.05(3 \mathrm{H} \mathrm{s})$ & $0.86 \mathrm{~s}$ & $0.84 \mathrm{~s}$ & & \\
28 & $1.07(3 \mathrm{H} \mathrm{s})$ & $1.07 \mathrm{~s}$ & $1.06 \mathrm{~s}$ & & $1.19 \mathrm{~s}$ \\
29 & - & & & & \\
30 & $* 1.31(3 \mathrm{H}, \mathrm{s})$ & $1.17 \mathrm{~s}$ & $1.16 \mathrm{~s}$ & $1.19 \mathrm{~s}$ & \\
\hline
\end{tabular}

*Significantly different chemical shifts

The HMBC measurements (Fig. 1) showed that compound 1 exhibited two-bond couplings between $\mathrm{H}-4$ and the C-3 carbonyl carbon, between $\mathrm{H}-4$ and C-5, as well as between $\mathrm{H}-1$ and C10. There is also a three-bond coupling between $\mathrm{H}-1$ and $\mathrm{C}-3$ and $\mathrm{H}-1$ and $\mathrm{C}-5$, confirming the structure of ring $\mathrm{A}$. The protons of the angular methyl H-30 couple with the carboxyl carbon, locating the carboxyl carbon to be attached to C-20. The proton at C-2 is coupled to C-1 only, unlike $\mathbf{2 b}$ and its derivatives $\mathbf{2} \mathbf{c}$ and $\mathbf{2 d}$ in which this proton is coupled to $\mathrm{C}-3, \mathrm{C}-4$ and $\mathrm{C}-10$.

The mass spectrum gave the molecular ion at $\mathrm{m} / \mathrm{z} 472$, with other significant peaks at 426 $(\mathrm{M}+-\mathrm{HCOOH}), 411\left(426-\mathrm{CH}_{3}\right), 290$ and 289, representing a fraction resulting from cleavage of ring $\mathrm{D}$ followed by loss of $\mathrm{H}, 207,189,177,175$. The base peak appeared at $\mathrm{m} / \mathrm{z} 155$, due to a fraction resulting from loss of $\mathrm{CH}_{3}$ and $\mathrm{H}_{2} \mathrm{O}$ from $\mathrm{M}^{+}$followed by cleavage of ring $\mathrm{D}$.

In addition to compound $\mathbf{1}$ a number of other known triterpenoids including the cytotoxic agent betulinic acid, betulonic acid, canophyllal, canophyllol, friedelin and a mixture of $\beta$ sitosterol and stigmasterol were also isolated for the first time from the plant. 
Table 3. Comparison of ${ }^{13} \mathrm{C}-\mathrm{NMR}$ spectra of $\mathbf{1}, \mathbf{2} \mathbf{a}, \mathbf{2} \mathbf{b}, \mathbf{3 b}$ and $\mathbf{3 c}$, Signals in $\mathrm{CDCl}_{3}, \delta \mathrm{ppm}$

\begin{tabular}{llllll}
\hline Carbons & \multicolumn{5}{c}{ Compounds } \\
\hline & $\mathbf{1}$ & $\mathbf{2 a}$ & $\mathbf{2 b}$ & $\mathbf{3 b}$ & $\mathbf{3 c}$ \\
1 & 32.6 & 22.2 & 29.4 & 22.3 & 28.2 \\
2 & 75.0 & 41.5 & 73.1 & 44.5 & 76.5 \\
3 & 212.4 & 213.3 & 213.3 & 212.6 & 208.1 \\
4 & 55.6 & 58.2 & 51.9 & 58.3 & 54.3 \\
5 & 43.1 & 42.1 & 42.4 & 42.1 & 43.1 \\
6 & 41.2 & 41.3 & 40.4 & 41.3 & 41.0 \\
7 & 18.1 & 18.2 & 17.7 & 18.2 & 18.2 \\
8 & 53.2 & 50.7 & 49.7 & 53.2 & 50.4 \\
9 & 37.4 & 37.4 & 36.3 & 37.5 & 36.6 \\
10 & 56.5 & 59.8 & 51.6 & 59.5 & 53.4 \\
11 & 35.3 & 35.4 & 34.4 & 35.5 & 35.1 \\
12 & 30.2 & 30.2 & 29.0 & 30.3 & 30.1 \\
13 & $39.7 *$ & 39.1 & 38.8 & 39.7 & 39.2 \\
14 & $38.1 *$ & 39.2 & 38.6 & 38.1 & 39.4 \\
15 & 32.8 & 29.7 & 28.5 & 32.8 & 30.4 \\
16 & 35.4 & 36.1 & 35.7 & 35.5 & 36.2 \\
17 & 29.6 & 30.1 & 29.8 & 29.5 & 29.1 \\
18 & 42.5 & 44.2 & 44.0 & 42.5 & 44.5 \\
19 & 31.3 & 29.5 & 29.8 & 31.4 & 36.9 \\
20 & 40.3 & 40.4 & 40.0 & 40.5 & 40.6 \\
21 & 28.2 & 29.5 & 29.5 & 28.6 & 29.9 \\
22 & 38.2 & 36.6 & 36.0 & 38.3 & 29.4 \\
23 & 6.5 & 6.2 & 6.0 & 6.8 & 6.5 \\
24 & 14.7 & 14.6 & 13.5 & 14.6 & 14.1 \\
25 & 17.8 & 18.0 & 17.0 & 17.6 & 18.4 \\
26 & 20.9 & 18.4 & 15.4 & 20.9 & 16.1 \\
27 & 17.7 & 16.3 & 17.9 & 17.6 & 17.5 \\
28 & 31.8 & 31.8 & 31.3 & 31.9 & 31.8 \\
29 & 183.3 & 184.5 & 178.6 & 31.8 & 31.9 \\
30 & 32.0 & 31.6 & 31.5 & 179.4 & 179.4 \\
\hline & & & & &
\end{tabular}

*Signals interchangeable. 


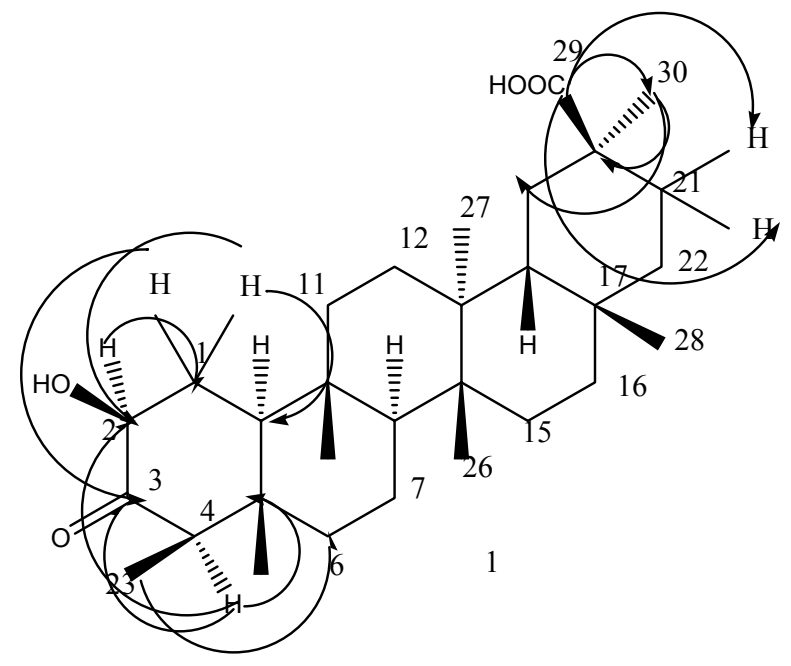

Figure 1

HPLC separation of a white crystalline solid obtained from repeated column chromatography of one of the fractions of the acetone extract gave seven homologous long chain esters of E-ferulic acid (4a-4g), with molecular ions $\mathrm{M}^{+}$at $\mathrm{m} / \mathrm{z}$ 516, 530, 544, 558, 572, 586 and 600. The most abundant of these was E-ferulic acid hexacosyl ester (4d), the others (4a, $\mathbf{4 b}, \mathbf{4 c}$, $\mathbf{4 e}, \mathbf{4 f}$, and 4g) being the tricosyl, tetracosyl, pentacosyl, heptacosyl, octacosyl and nonacosyl esters respectively. These compounds were characterised by spectroscopic methods (UV, including shift behaviour on addition of $\mathrm{NaOH},{ }^{1} \mathrm{H} \mathrm{NMR},{ }^{13} \mathrm{C} \mathrm{NMR}, \mathrm{MS}$ ) and comparison of the resulting data with those reported in the literature. ${ }^{11,12}$ All these compounds are reported for the first time in Dichapetalum barteri.<smiles>[R]OC(=O)/C=C/c1ccc(O)c(OC)c1</smiles>

4a, $\mathrm{R}=\mathrm{CH}_{3}\left(\mathrm{CH}_{2}\right)_{22} ; 4 \mathrm{~b}, \mathrm{R}=\mathrm{CH}_{3}\left(\mathrm{CH}_{2}\right)_{23} ; 4 \mathrm{c}, \mathrm{R}=\mathrm{CH}_{3}\left(\mathrm{CH}_{2}\right)_{24} ; 4 \mathrm{~d}, \mathrm{R}=\mathrm{CH}_{3}\left(\mathrm{CH}_{2}\right)_{25}$ $4 \mathrm{e}, \mathrm{R}=\mathrm{CH}_{3}\left(\mathrm{CH}_{2}\right)_{26} ; 4 \mathrm{f}, \mathrm{R}=\mathrm{CH}_{3}\left(\mathrm{CH}_{2}\right)_{27} ; 4 \mathrm{~g}, \mathrm{R}=\mathrm{CH}_{3}\left(\mathrm{CH}_{2}\right)_{28}$ 


\section{Experimental Section}

General Procedures. Mps uncorr; Column chromatography, silica gel 60 (Fluka), TLC:0.25 mm silica gel N/UV 254 (Macherey-Nagel), detection by $\mathrm{UV}_{254}$ and by anisaldehyde reagent No 15 according to Stahl [13] UV in $\mathrm{MeOH},{ }^{1} \mathrm{H}-\mathrm{NMR}$ at $360 \mathrm{MHz}$ and ${ }^{13} \mathrm{C}-\mathrm{NMR}$ at $90 \mathrm{MHz}$ on a Brüker AM 360 instrument, in $\mathrm{CDCl}_{3}$ unless otherwise stated, $\delta$ in ppm, TMS as internal standard. EI-MS on a Finnigan TSQ 700 instrument $70 \mathrm{eV}, \mathrm{m} / \mathrm{z}$ (rel. int $>10 \%$ unless key ions.

Plant materials. The stem bark of Dichapetalum barteri was collected from a forest grove at Pokuase near Accra. Identification was by (the late) Mr. A. A. Enti, former Curator of the National Herbarium and, Department of Botany, University of Ghana Legon CEO of Forestry Enterprises Limited. Voucher specimens are deposited at the National Herbarium at the University of Ghana, Legon.

\section{Extraction and isolation}

2ß-hydroxy-3-oxo-D:A-friedooleanan-29-oic acid 1. The air-dried and pulverised stem bark $(1.4 \mathrm{~kg})$ was first defatted by Soxhlet extraction with petrol $\left(60-80^{\circ}\right)$. From this extract was obtained mainly fredelan-3-one, D:A friedo-oelanan-3 $\beta$-ol (epifriedelinol) and $\beta$-sitosterol. The plant material was then further extracted for 48 hours with methanol to yield a brown sticky mass $(7.88 \mathrm{~g})$. This was chromatographed on a silica gel column with petrol: $\mathrm{CHCl}_{3}$ of increasing polarity to give five main fractions. Trituration of the solid from the second fraction with acetone and subsequent recrystallisation from methanol gave pale yellow to off-white needle-like crystals of 1 (14.5 mg), mp 199-201, UV inactive, brown with anisaldehyde reagent. ${ }^{1} \mathrm{H}$ and ${ }^{13} \mathrm{C}$ Spectroscopic data see tables. MS (rel. int. \%) m/z $472\left(\mathrm{M}^{+}, 8\right), 426(14), 411$ (7), 373 (7), 318 (14), 284 (30), 264 (22), 207 (15), 191 (44), 163 (81), 155 (100), 109 (44), 69 (45), 55 (58).

Other constituents obtained from the methanol extract were a homologous series of long chain fatty acids (C-16 to C-30), characterised as the methyl esters by GC-MS.

Ferulic acid Esters (4a - 4h). Dried and pulverised stem bark $(2.8 \mathrm{Kg})$ was percolated with cold acetone for 48 hours to give a viscous syrup $(55 \mathrm{~g})$. Repeated fractionation of $9 \mathrm{~g}$ of this syrup by column chromatography using petrol: $\mathrm{CHCl}_{3}$ of increasing polarity yielded six main fractions. Further purification of fraction 1 gave mainly friedelan-3-one and friedelan $3 \beta$-ol. The second and third fractions were combined and rechromatographed with petrol:EtOAc $(15: 1)$ to yield a white solid (106 mg), recrystallised from methanol, violet with anisaldehyde reagent, fluorescing intense blue in UV mp 77-78 . Further purification by preparative HPLC yielded seven longchain esters of ferulic acid with $\mathrm{C}_{23}$ to $\mathrm{C}_{29}$ moieties, with the hexacosyl ester (20 mg) being the most abundant. IR $v_{\max } 3525,2850,1725,1640,1605,1520,1450,1370,1320,1290,1275$, $1220,1175,1150,1125,1030,930,915,885,825,805$ and $730 \mathrm{~cm}^{-1}$. UV $\lambda_{\max } 216,234(\mathrm{sh})$, 297, $324 \mathrm{~nm}$; + NaOH 212, 250,300,308, $377 \mathrm{~nm}$. Other spectroscopic characteristics in agreement with the literature $[11,12]$. The yields of the other esters from the HPLC separation were tricosyl ester $(0.2 \mathrm{mg})$, tetracosyl ester $(5.2 \mathrm{mg})$, pentacosyl ester $(3.8 \mathrm{mg})$, heptacosyl ester $(2.0 \mathrm{mg})$, octacosyl ester $(2.2 \mathrm{mg})$ and nonacosly ester $(2.6 \mathrm{mg})$. 
Other compounds obtained from the acetone extract are betulonic acid, betulinic acid, syncanophyllol and syn-canophyllal.

\section{Acknowledgements}

A study leave with pay granted to one of us (S A-K) by the Ministry of Education of Ghana through the Ghana Education Service is gratefully acknowledged. Thanks are also due to the Deutsche Forschungsgemeinschaft and the Fonds the Chemischen Industrie in Germany for financial support.

\section{References}

1. Dalziel, J. M.; Hutchinson, J. Useful Plants of West Tropical Africa. Crown Agents: London, 1955; p 171.

2. Peters, R. Endeavour 1954, 13, 147.

3. Eloff, J. N.; Grobbelaar, N. Phytochemistry 1969, 8, 2201.

4. Desai, H. K.; Gawad, D. H.; Govindachari, T. R.; Joshi, B. S.; Kamat, V. N.; Modi, J. D.; Mohamed, P. A.; Parthasarathy, P. C; Patankar, S. J.; Sidhaye, A. R.; Viswanathan, N. Indian J. Chem.1970, 8, 851.

5. Achenbach, H.; Asunka, S. A.; Waibel, R.; Addae-Mensah, I.; Oppong, I. V. Nat. Prod. Letters 1995, 7, 93.

6. Addae-Mensah, I.; Waibel, R.; Asunka, S. A.; Oppong, I. V.; Achembach, H. Phytochemistry1996, 43, 649

7. Hall, R. J. New Phytol. 1972, 71, 855.

8. Nwude, N.; Parsons, L. E.; Aduadi, O. A. Toxicology 1977, 7, 23.

9. Estrada, R.; Cardenas, J.; Baldomero, E.; Rodrigues-Hahn, L. Phytochemistry 1994, 36, 747.

10. Gonzalez, N. L.; Alvarenga, A. G.; Ravelo, I. A.; Bazzochi, I. L. J. Natural Products 1995, $58,570$.

11. Achenbach, H.; Stőcker, M.; Constenla, M. A. Z. Naturforsch.1986, 41c, 164.

12. Addae-Mensah, I.; Achenbach, H.; Thoithi, G. N.; Waibel, R.; Mwangi, J. W. Phytochemistry 1992, 31, 2055.

13. Stahl, E. Dunnschichtchromatographie $2^{\text {nd }}$ Edn., Springerl-Verlag: Berlin, 1962. 